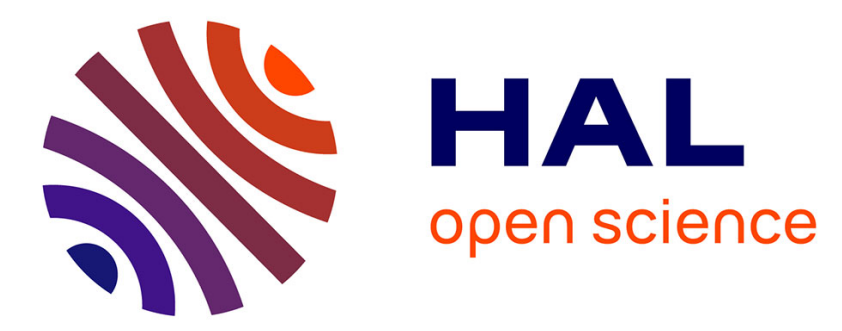

\title{
OPTIMAL RECONFIGURATION POLICY TO REACT TO PRODUCT CHANGES
}

Andrea Matta, Maurizio Tomasella, Matteo Clerici, Silvia Sacconi

\section{To cite this version:}

Andrea Matta, Maurizio Tomasella, Matteo Clerici, Silvia Sacconi. OPTIMAL RECONFIGURATION POLICY TO REACT TO PRODUCT CHANGES. International Journal of Production Research, 2008, 46 (10), pp.2651-2673. 10.1080/00207540701452159 . hal-00512990

\section{HAL Id: hal-00512990 https://hal.science/hal-00512990}

Submitted on 1 Sep 2010

HAL is a multi-disciplinary open access archive for the deposit and dissemination of scientific research documents, whether they are published or not. The documents may come from teaching and research institutions in France or abroad, or from public or private research centers.
L'archive ouverte pluridisciplinaire HAL, est destinée au dépôt et à la diffusion de documents scientifiques de niveau recherche, publiés ou non, émanant des établissements d'enseignement et de recherche français ou étrangers, des laboratoires publics ou privés. 


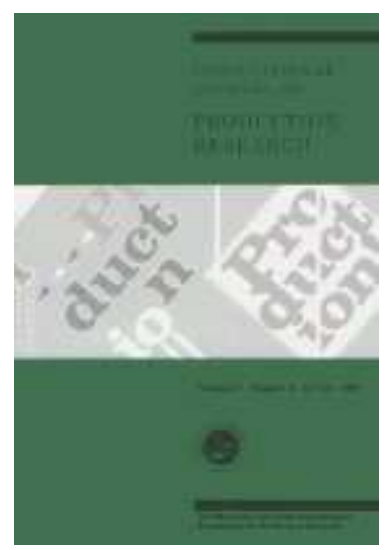

OPTIMAL RECONFIGURATION POLICY TO REACT TO PRODUCT CHANGES

\begin{tabular}{|c|c|}
\hline Journal: & International Journal of Production Research \\
\hline Manuscript ID: & TPRS-2007-IJPR-0235 \\
\hline Manuscript Type: & Original Manuscript \\
\hline $\begin{array}{l}\text { Date Submitted by the } \\
\text { Author: }\end{array}$ & 29-Mar-2007 \\
\hline Complete List of Authors: & $\begin{array}{l}\text { Matta, Andrea; Politecnico di Milano, Dipartimento di Meccanica } \\
\text { Tomasella, Maurizio; Politecnico di Milano, Dipartimento di } \\
\text { Meccanica } \\
\text { Clerici, Matteo } \\
\text { Sacconi, Silvia }\end{array}$ \\
\hline Keywords: & $\begin{array}{l}\text { CAPACITY PLANNING, RECONFIGURABLE MANUFACTURING } \\
\text { SYSTEMS }\end{array}$ \\
\hline Keywords (user): & RECONFIGURATION, OPTIMAL POLICY \\
\hline
\end{tabular}

\section{(s) ScholaroNE \\ Manuscript Central}




\title{
OPTIMAL RECONFIGURATION POLICY TO REACT TO PRODUCT CHANGES
}

\author{
A. MATTA $\dagger^{*}$, M. TOMASELLA $\dagger$, M: CLERICI, S. SACCONI
}

$\dagger$ Dipartimento di Meccanica, Politecnico di Milano, via Bonardi 9, 20133 Milano

Correspondence $\quad *$ Andrea Matta. Email: andrea.matta@polimi.it

The increasing frequency of product and process modifications may significantly mine the profitability of those production systems which are designed in a traditional way by considering only the current product requirements and, eventually, the expectations on future variations of the market volumes. Indeed, the product typically evolves during its life cycle, by changing its technological characteristics and therefore its requirements on the production system. As a consequence, the production system may be forced to run inefficiently and costly because it is no longer consistent with the modified product. This paper describes the reconfiguration problem of production systems and proposes the optimal reconfiguration policy to react to product changes on uniformly distributed market demand and uniformly distributed technological requirements. A numerical case based on a real problem supports the applicability of the proposed reconfiguration policy.

Keywords: optimal policy, reconfiguration, Reconfigurable Manufacturing Systems, capacity planning

\section{Introduction}

In recent years, due to the global competition, companies often have to be able to operate in a dynamic environment, where products need to be frequently modified or even to be replaced, and production volumes considerably change from one time period to another, following the market demand. Changes in process technologies and in government regulations should also be faced with an increasing frequency. In such an environment, the enterprise must choose the manufacturing strategy that best allows to achieve sustainable and competitive production systems, which will be used to provide the market with the products it asks for.

The design phase of the production system will determine, together with the system management phase, the system performance over time. For this reason, the manufacturer should pay a lot of attention to the design phase, also taking into account that the life of production systems is often longer than the life of the products it has to produce. However, production systems are traditionally designed on the basis of current information on the product and, eventually, of forecasts on expected future production volumes. Moreover, if there are quite high possibilities that the product characteristics will change during its life cycle, the manufacturer 
generally selects flexible equipments; on the contrary, the equipment is designed on the current product characteristics if the product is not expected to undergo relevant modifications in the future.

Most manufacturing companies use a portfolio of both dedicated and flexible production systems. Dedicated production systems are typically used to produce the company's products requiring the highest value of the production volume and are usually designed around each single part type. Flexible production systems provide lower throughputs, but they can be used to produce a large variety of products. They generally consist of general purpose CNC (Computer Numerically Controlled) machines, integrated into a unique system. Each of the two classes of production systems has its own limitations and advantages (Koren et al. 1999, Matta and Semeraro 2005). As usual when comparing two opposite solutions to the same problem, the advantages of the first become limitations when related to the second, and vice versa. Each dedicated production line is typically designed to produce a single part type at high production rates, by using several tools simultaneously onto the same machine. When the demand is sufficiently high, the production cost per single piece becomes very low. However, dedicated lines could loose their cost-effectiveness when they do not operate at their full capacity (Matta et al. 2000). Flexible production systems are based on high equipment cost (CNC machines perform singletool operations, with nearly all functionalities already built-in) and low throughput, thus the cost per single piece results higher.

By using capacity and functionality as coordinates to measure the differences between the two approaches (Koren et al. 1999), one can see that dedicated systems provide very low functionality, in the sense that they usually produce only one product type, where flexible solutions provide high functionality, as they are able to produce multiple products. The opposite holds when the capacity of the production system is considered. However, in both cases it is not simple to reconfigure the system and to change the value of one or both of these coordinates, because the cost variation between different either capacity or functionality solutions is often very high.

Reconfigurable Manufacturing Systems (RMS) are designed at the outset for rapid change in structure, as well as in hardware and software components, in order to quickly adjust production capacity and functionality within a part family, in response to sudden changes in market or in regulatory requirements. The term adaptive production is also used to refer to those production systems easily adaptable, with low efforts, to face modifications of products and production volumes. In Koren et al. (1999), the RMS paradigm is presented. The critical point of such systems relates to how to introduce the reconfigurability or adaptability into production systems in an efficient and cost-effective way. A first problem is that a system reconfiguration could take place if both the hardware and the software components can be reconfigured at the desired level of detail (e.g. at the system level, at the machine tool level, at the control level, at the feed drives level, etc.). However, new technologies enabling reconfiguration are emerging in these years, such as modular and open architecture system controllers and modular machine tools. Another problem concerns the analysis and modelling of production requirements over time, needed as a prerequisite to define which different configuration solutions for the same production system are needed to satisfy these requirements and which solutions appear to be the best.

In the present context, the evolution of the production system has to match closely with that of the products it manufactures. Therefore, a change of products may force a change of the production system, thus also causing additional investments; however the production system can be easily modified to react to one ore more product changes only if the whole evolution of products is considered when the decision concerning the reconfiguration of the production system is made.

In order to accommodate these changes, originated for instance by a modification of one of the product features, or by the change of the product material, or again by the introduction of a new product variant, or by the structural increase of production volumes, etc., new functions must be added to the manufacturing system (e.g. an additional spindle unit, or a new station) and/or existing functions must be adapted (e.g. the stroke of a motion axis, or the capacities of existing buffers). In this paper, the change action introduced into the production system is called a system reconfiguration. In general, for each kind of change in the production requirements, a http://mc.manuscriptcentral.com/tprs Email: ijpr@lboro.ac.uk 
different type of reconfiguration is needed. The common denominator for all of these different kinds of changes, is that for each reconfiguration period occurring during the lifetime of a system, a so-called ramp-up period takes place. The expression ramp-up period stands for the time interval it takes a newly introduced or just reconfigured manufacturing system to reach sustainable, longterm levels of production in terms of throughput and part quality, considering the impact of equipment and labour on productivity (Koren et al. 1999). Shortening these periods is one of the main problems concerning the reconfiguration of manufacturing systems. In such a context, new models for addressing the production system reconfiguration problem are needed; these models should be characterized by an integrated view of product and production system evolutions. Indeed, the technological product characteristics change, driven internally by the continuous improvement of the enterprise processes, and at the same time driven externally by the market. Thus, the production system may evolve because of the need to properly tune its capacity and functionality, in order to match with the product characteristics.

This paper deals with the problem of production system reconfiguration. The key issue of this work bases on the idea that a change into the production system may be more effective if the future evolution of products is taken into account during the reconfiguration phase (Matta and Tomasella 2005). This is relevant in all those contexts affected by high uncertainty, where technological product characteristics change at high frequencies. In particular, the paper proposes the optimal policy to decide when and how to reconfigure the production system under uncertain market demand and technological product characteristics.

The outline of the paper looks as follows. Section 2 describes the reference context in which the reconfiguration problem is approached. Section 3 outlines the main aspects of the approach by describing the product evolution, the reconfiguration problem and its optimal policy. Section 4 provides some numerical considerations on the derived optimal reconfiguration policy, and finally conclusions are drawn in Section 5.

\section{The reconfiguration problem}

\subsection{Product evolution and reconfiguration problem}

The product modifications are considered, as well as their evolution over time, to be the drivers for the production system reconfiguration. Some basic concepts, fundamental to describe and analyse this driving role, are defined in the following.

Product functionality is defined as the vector of product characteristics the production system must be able to manufacture, and depends on the set of product features that must be realized. System functionality is the vector of system characteristics enabling the production process. If the system functionality matches with the product functionality, it is assumed that the production system is able to manufacture the product at certain levels of production volumes.

Finally, system capacity is defined as the amount of good finished pieces the production system is able to produce during a certain time period. Capacity depends both on product and system functionalities, thus it generally changes during the product and production system evolutions. For example, capacity may decrease when processing times increase, e.g. because of the increased dimensions of the surfaces to be worked, or it may also increase due to a product improvement allowing faster operations in production.

The detailed system reconfiguration is a difficult task to deal with, in particular for its high level of detail and high uncertainty of the information needed. A given configuration for a certain production system is intended as the complete and detailed set of resources belonging to the system, such as machine tools, buffers, fixtures, pallets, etc., needed in order to meet the requirements of a given production problem. After having defined the expected evolution of production requirements, i.e. of the technological product 
specifications and of the market volumes, in terms of evolution scenarios, the decision maker (the system designer) has to identify in each scenario the reconfiguration alternatives that are suitable to accomplish the product needs. Each alternative configuration therefore depends on the specific scenario and is mainly constrained by the budget available, by the technical specifications required for the product, i.e. the product functionality, and by the requested production volume in that scenario.

Different configurations belonging to the same scenario generally lead to different performance results, e.g. in terms of throughput or operating costs. Therefore one could decide, when a change in the production requirements occurs, i.e. when a given scenario takes place, that the configuration with the maximum throughput or minimum cost should be chosen as the new configuration for the system, and then to reiterate this behaviour for the following scenario changes and related reconfiguration choices. One first problem with such an approach is that, given the best configuration for a generic scenario $A$ and the best configuration for another scenario $B$, possibly occurring after $A$, it may happen that the reconfiguration is not technically feasible or at least not affordable with low cost. A second problem is that if this ever shows to be feasible, the choice on how to reconfigure the system from the first to the second configuration may lead to non-optimal overall results, given the possibility that new changes could be required in the future. Therefore, a global approach must be considered, and this approach must take into account all the scenarios with their related probabilities and alternative configurations, over the whole sequence of stages considered.

This problem is known as a dynamic and stochastic problem, in which scenarios are uncertain and the decision maker pursues the goal of minimizing a total expected (discounted) cost function over a defined finite sequence of time periods. The problem has been solved up to now concerning the production volume as the one and only requirement to system reconfiguration, and for this reason it is commonly referred to as the capacity management problem.

\subsection{Brief literature review}

This section provides a quick overview on the main contributions concerning the problem of managing the capacity of a production system. The problem of managing both capacity and functionality is quite recent and no considerable work has been published on this topic, to the best of the authors' knowledge. However, literature on the capacity management problem can help to understand the above described problem and how to address it, even only in the simplest cases.

An important contribution is given by the survey from Luss (1982), which provides a synthesis of the eldest approaches to the problem. The most valuable works cited by Luss range from the very first approaches to the problem (Manne 1961, Manne 1967 and Sinden 1960) to more sophisticated ones (Freienfelds 1980). Manne (1961) proposes an optimal capacity expansion policy based on the definition of an optimal and constant expansion quantity; the problem is modelled with continuous time and finite time horizon, deterministic and linear product demand, and a linear expansion cost function. The approach proposed by Sinden (1960) considers on the opposite an expansion policy driven by the optimal constant value for the time between one expansion and another. Freienfelds (1980) proposes a birth-death stochastic model, as well as the deterministic equivalent one, and relaxes some of the traditional hypotheses, such as the linearity of the product demand.

A last contribution following Manne's and Freienfelds' approaches is the one from Bean et al. (1991), which further relaxes some other hypotheses, e.g. by allowing the product demand be modelled by any stochastic process.

Some other works consider the capacity expansion problem with two different kinds of facility, each one able to meet the demand of one product type, with the possibility of converting a facility from one type to the other (Fong and Rao 1975, Luss 1979).

After the survey from Luss, many other contributions follow. Davies et al. (1987) and do Val and Salles (1999) are some of the most interesting works. In particular, do Val and Salles (1999) provides a very detailed characterization of the optimal policy and of the http://mc.manuscriptcentral.com/tprs Email: ijpr@lboro.ac.uk 
behaviour of the decision maker when guided by it. Rocklin et al. (1984) proposes to represent the problem such as a traditional inventory management problem modelled as a Markov Decision Process. This work is first revisited by Angelus and Porteus (1996) and again by Angelus et al. (1997), with a reformulation of the problem taking into account both costs and profits related to capacity expansion and assuming a more complex kind of demand, to be more adherent to reality; an application to modular semiconductor wafer factories is also provided.

The common characteristic for the papers cited up to this point is that all of them only consider the possibility of expanding the capacity of the system. This hypothesis is relaxed by Asl and Ulsoy (Asl and Ulsoy 2002a), which considers both capacity expansion and reduction problems, again by the use of Markov Decision Theory. This paper derives the optimal expansion/reduction policy in the case of stochastic market demand, where the demand can follow any type of probability distribution, and it also investigates the case in which there is a considerable time delay between the time when, for example, the decision of adding new capacity is made, and the time instant when the capacity is actually available at the shop floor level. The same authors present an approach (Asl and Ulsoy $2002 \mathrm{~b}$ ) based on feedback control theory, showing that the availability of proper feedback can provide suboptimal solutions to the problem.

Summarizing, literature on the capacity management problem only deals with capacity expansion/reduction possibilities, without considering the technological preferences the same market may require. This new issue, if not adequately considered, might considerably modify the optimal expansion and reduction policies.

\section{Optimal reconfiguration policies}

\subsection{Assumptions and notation}

Product evolution is described in terms of demand levels and product functionality required by the market in each discrete time period. Symbols $D_{k}$ and $P F_{k}$ are used to respectively denote the product quantity and functionality the market requires at period $k$, with $k=0,1, \ldots, N-1$. The planning horizon is finite and, for sake of simplicity, time periods are deterministic with duration $T_{k}$. A further simplification is introduced by considering $P F_{k}$ as a scalar value instead of a more complex vector representing several kinds of functionalities. Some examples of scalar product functionality can be one of the product dimensions, the needed machine power to manufacture the product, the tolerance or surface roughness, etc. $D_{k}$ and $P F_{k}$ are assumed to be random non-negative continuous variables; in particular the market stochastic evolution is described by the joint probability distribution $\Psi_{k}\left(P F_{k} ; D_{k}\right)$, which is assumed to be independent on the joint distributions of previous periods.

For the system functionality, denoted with $S F_{k}$, the same simplification as that of the product functionality is introduced, assuming only one capability of the production system is considered and represented by the scalar value $S F_{k}$. Examples of such a capability can be the stroke of the machine feed drives, the available spindle power, the machining accuracy, etc; obviously, this capability must be of the same nature of the considered product functionality. The characterization of production systems in few kinds of functionalities is still an open issue which is not faced in this paper, where this assumption is only due to the need of developing the simplest model considering both system functionality and capacity aspects. An exhaustive work on the relationships between product and system functionality is that of Gindy and Ratchev (1998).

System capacity is denoted with $C_{k}$. At each period $k$, the system capacity depends on the duration $T_{k}$, on the system functionality $S F_{k}$ and on the cycle time necessary to process the product. Since the product cycle time is a function of the requested product functionality and the machine parameters to perform it, system capacity is described by a function of the following nature:

http://mc.manuscriptcentral.com/tprs Email: ijpr@lboro.ac.uk 


$$
C_{k}=f\left(T_{k}, P F_{k}, S F_{k}\right)
$$

The presence of the term $S F_{k}$ in equation (1) is due to the fact that the production system can manufacture the product, i.e. can offer a positive system capacity, only if its functionality allows that. If this hypothesis does not hold, the system capacity is identically equal to zero.

The specific relationship between system capacity and product functionality closely depends on the type of manufacturing system considered in each singular case. In the present paper, the following general form is considered:

$$
C_{k}\left(S F_{k}\right)=\left\{\begin{array}{cl}
\frac{T_{k} \cdot \mu}{P F_{k}} & \text { if } S F_{k} \geq P F_{k} \\
0 & \text { if } S F_{k}<P F_{k}
\end{array}\right.
$$

where $\mu$ is a speed factor, characteristic of the production system; obviously other different capacity functions can be proposed to represent different cases. In the present work, system capacity is therefore defined to be directly proportional to the time available in the period and to the speed factor of the equipment, and inversely proportional to the product functionality. The higher the product functionality, the smaller the capacity becomes. An insight into the meaning of all of the quantities cited by equation (2) will be provided in Section 4 by means of realistic examples.

The problem of the manufacturer is then to select at each period the system functionality and the speed factor which minimize a given expected total discounted cost function, over the whole sequence of periods. In the proposed model it is assumed that the speed factor is given: therefore the only decision variable is represented by the system functionality. The decision making model is described in the following sub-section and then solved in Section 3.3.

\subsection{Model description}

At each period $k$, the manufacturer has to decide which functionality the production system should have in order to face the market uncertainties. If the system functionality is expanded/reduced, the system is said to be reconfigured. The sequence of reconfiguration decisions is called the reconfiguration policy. This reconfiguration policy is chosen by pursuing the minimization of a given total expected discounted cost function over the whole planning period. In the following, the structure of this cost function is described in detail.

The total expected discounted cost of the problem is defined as the accumulation over time of the so-called control cost $\left(C C_{k}\right)$, which represents the cost incurred in each period $k$ as a consequence of the decision made in period $k$, and also depending on the value of the system functionality at the beginning of the same period (3). This cost is defined as the sum of the expected operating cost incurred in the period $\left(E O C_{k}\right)$, due to the fact that the system operates with system functionality $S F_{k}$, and of the functionality management cost $\left(M_{k}\right)$, directly related to the decision made in period $k$ :

$$
C C_{k}\left(k, u_{k}\right)=E O C_{k}\left(S F_{k}\right)+M_{k}\left(u_{k}\right)
$$

http://mc.manuscriptcentral.com/tprs Email: ijpr@lboro.ac.uk 
where $u_{k}$ is the difference between system functionalities of two adjacent periods, as effect of expansion or reduction investment at period $k$ :

$$
u_{k}=S F_{k+1}-S F_{k}
$$

Equation (4) means that, for instance, when a system functionality expansion is decided in period $k$, i.e. $u_{k}>0$, the new level of system functionality $S F_{k+1}$ is assumed to be available at the shop floor level only at the beginning of the following period, namely $k+1$.

The expected operating cost in period $k$ is the sum of the Expected Production Cost $\left(E P C_{k}\right)$, of the Expected Ramp-Up Production Cost $\left(E R U P C_{k}\right)$, of the Expected Shortage Cost $\left(E S C_{k}\right)$, and of the Expected Holding Cost $\left(E H C_{k}\right)$. All these expected values are computed with respect to the possible values of $D_{k}$ and $P F_{k}$ in period $k$, and with respect to the given joint distribution $\Psi_{k}\left(P F_{k}\right.$; $\left.D_{k}\right)$. Formally:

$$
\begin{gathered}
E O C_{k}\left(S F_{k}\right)=E P C_{k}\left(S F_{k}\right)+E R U P C_{k}\left(S F_{k}\right)+E S C_{k}\left(S F_{k}\right)+E H C_{k}\left(S F_{k}\right) \\
E P C_{k}\left(S F_{k}\right)=E_{D_{k}, P F_{k}}\left[P C_{k}\left(S F_{k}\right)\right]=E_{D_{k}, P F_{k}}\left[\left(\gamma_{P}-P\right) y_{k}\right] \\
E R U P C_{k}\left(S F_{k}\right)=E_{D_{k}, P F_{k}}\left[R U P C_{k}\left(S F_{k}\right)\right]=E_{D_{k}, P F_{k}}\left[\left(\gamma_{P}^{\prime}-\gamma_{P}\right) w_{k}\right] \\
E S C_{k}\left(S F_{k}\right)=E_{D_{k}, P F_{k}}\left[S C_{k}\left(S F_{k}\right)\right]=E_{D_{k}, P F_{k}}\left[\gamma_{S} z_{k}\right] \\
E H C_{k}\left(S F_{k}\right)=E_{D_{k}, P F_{k}}\left[H C_{k}\left(S F_{k}\right)\right]=E_{D_{k}, P F_{k}}\left[\gamma_{H} S F_{k}\right]=\gamma_{H} S F_{k}
\end{gathered}
$$

Parameters $\gamma_{P}$ and $P$ in equation (6) represent the unit production cost and the selling product price respectively; notice that $\left(P\right.$ - $\left.\gamma_{P}\right)$ is the marginal product value. Quantity $y_{k}$ represents the production level in period $k$. Assuming for simplicity that no inventory management is allowed in this firm, or equivalently that all the pieces produced can in any case be sold in the market, this quantity is defined as:

$$
y_{k}=\min \left(D_{k}, C_{k}{ }^{R}\right)
$$

where $C_{k}^{R}$ is the real (actual) capacity available in period $k$. Notice that this capacity is generally lower (and always not greater than) the potential capacity level, represented by $C_{k}$, formerly defined by equation (1). The term $C_{k}{ }^{R}$ takes into consideration capacity losses into the analysis, in particular those related to the ramp-up period (defined in Section 1) typically following each reconfiguration of the production system.

Parameter $\gamma_{P}^{\prime}$ in equation (7) represents the unit production cost during the ramp-up period, which is generally greater than $\gamma_{P}$. Quantity $w_{k}$, representing the total amount of pieces produced during the ramp-up period, is defined as: 


$$
w_{k}=\min \left(D_{k}, C_{k}^{R U}\right)
$$

where $C_{k}^{R U}$ is the total system capacity during the ramp-up period. This quantity can be at least roughly estimated if the duration of the ramp-up period can be quantified, and is often a significant fraction of $C_{k}^{R}$. The term $E R U P C_{k}$ has the purpose of taking into consideration a second major effect of the ramp-up phenomenon, i.e. the fact that, due to the lower yields and throughput affecting system ramp-up, production during the ramp-up is less efficient and thus costs more than production "at steady-state".

Parameter $\gamma_{S}$ in equation (8) represents the unit shortage cost incurred for each product unit of unmet market demand in period $k$. Quantity $z_{k}$ is equal to the level of unmet demand in period $k$, according to:

$$
z_{k}=\max \left(0, D_{k}-C_{k}^{R}\right)
$$

Finally, parameter $\gamma_{H}$ in equation (9) is the holding cost per unit of system functionality. This represents the unit cost to maintain the current level of system functionality available in period $k$.

The function $M_{k}\left(u_{k}\right)$ in equation (3) represents the management cost for expanding or reducing the system functionality. A similar function has been proposed by Asl and Ulsoy (2002a) in their capacity expansion and reduction problem. The following equation provides a formal definition.

$$
M_{k}\left(u_{k}\right)=\underbrace{L\left(u_{k}\right) \cdot\left(E+e \cdot u_{k}\right)}_{\text {expansion cost }}+\underbrace{L\left(-u_{k}\right) \cdot\left(R+r \cdot u_{k}\right)}_{\text {reduction cost }}
$$

with :

$$
L\left(u_{k}\right)=\left\{\begin{array}{lll}
1 & \text { if } & u_{k}>0 \\
0 & \text { if } & u_{k} \leq 0
\end{array}\right.
$$

where $E$ (or $e$ ) and $R$ (or $r$ ) represent the fixed (or the variable) expansion and reduction costs respectively. In particular, $E$ represents the setup cost to install additional system functionality, and $e$ is the unit ordering cost. On the other hand, $R$ represents the one-period labour cost to uninstall excess system functionality, and $r$ is the reward of selling one unit of system functionality.

At this point, it is worth re-analyzing in detail the breakdown of the single-period control cost $\left(C C_{k}\right)$ presented by equations (3) through (13) and the related implications on the solution of the reconfiguration problem.

First, we remind that the nature of system reconfigurations considered in the present paper is explicitly physical (hard). This means that only reconfigurations at the hardware level, of both system functionality and capacity, are taken into account by the model variables and parameters. Indeed, in principle, logical (soft) reconfigurations, involving only software aspects of the production system could also be considered. Therefore, the present model can be used for instance to decide when/how to replace a machine module/element with another one offering a higher level of $S F_{k}$ (e.g. one spindle unit with another one characterized by a higher power), or when/how to replace a machine (e.g. one machining centre with another one characterized by a bigger working cube). On

http://mc.manuscriptcentral.com/tprs Email: ijpr@lboro.ac.uk 
the opposite, this model cannot be used to decide, for instance, software types of capacity augmentation, such as the use of additional production shifts or of subcontracting.

Second, the object of the decision is the level of system functionality, and in particular the amount of system functionality to be expanded/reduced $\left(u_{k}\right)$ by the start of the following period, given the knowledge of the current value of system functionality $\left(S F_{k}\right)$, of the current system capacity $\left(C_{k}\right)$ and of the joint distribution of the random phenomena involved in the problem $\left(\Psi_{k}\left(P F_{k} ; D_{k}\right)\right)$. The levels of system functionality $\left(S F_{k+1}\right)$ and capacity $\left(C_{k+1}\right)$ for the immediately following period result as a consequence of this decision, according to equations (4) and (2) respectively.

Third, the reconfiguration costs included into the equations above, go beyond considering only the ordering cost of new hardware modules, in case of functionality expansion, or only the return from selling extra functionality, in case of reduction: in fact, ramp-up costs are also included in the model.

Finally, other costs related to system reconfiguration and not explicitly mentioned in the definitions above, can be considered as a portion of the constant terms $E$ and $R$ in the definition of function $M_{k}\left(u_{k}\right)$.

\subsection{Problem Statement}

The described problem is a Markov Decision Problem over a discrete-time finite horizon of $N$ periods, where at each period $k$ the manufacturer has to decide the control action $u_{k}$, with $k=0, \ldots, N-1$. The values of the system functionality, of the system capacity, and of the product demand and functionality requested by the market define the state of the process at each period. Since continuous domains for both product demand and functionality were assumed, the number of possible states at each period is infinite. Whenever the process enters a new period, it is assumed that the manufacturer observes the new state, incurs the operating costs related to that state and then takes the control action $u_{k}$ to decide a new value for the system functionality to be available by the start of the following period.

Thus, given available an initial state $\left(X_{0}\right)$ at the starting period, the problem is to find an optimal reconfiguration policy, i.e. a policy $\pi^{*}=\left\{u_{0} *, \ldots, u_{K-1} *\right\}$, not necessarily unique, which minimizes the following total expected discounted cost:

$$
J_{\pi} *\left(X_{0}\right)=\min _{\pi} E\left\{-\alpha^{N} \gamma_{N} S F_{N}+\sum_{k=0}^{N-1} \alpha^{k} C C_{k}\left(k, u_{k}\right)\right\}
$$

where $\alpha$ is a discount factor (for simplicity assume that $0 \leq \alpha \leq l$ ), $S F_{N}$ is the terminal value of system functionality at the last period, and $\gamma_{\mathrm{N}}$ is the salvage value per unit of terminal system functionality, at the end of the considered horizon. The symbol ' $E$ ' stands for the expected value of the cost function in brackets, and is computed over all the possible values of the state of the process and over the whole sequence of periods.

A fundamental solution technique to this kind of problem is based on the concept of Dynamic Programming (DP) (Bertsekas, 1987). By using this technique, it is generally possible to derive a policy which is simultaneously optimal for every initial state. Moreover, in situations where decisions are made in stages while gathering information on the state of the process, a so-called closed-loop minimization of the cost takes place (Bertsekas, 1987). This means that, when updated information on the state of the process is available, this information can be exploited to make better decisions. In such cases, e.g. in the Markov Decision Problem defined http://mc.manuscriptcentral.com/tprs Email: ijpr@lboro.ac.uk 
above, the decision maker is interested not in finding a sequence of numerical values for the optimal control action $u_{k}{ }^{*}$, but rather in finding a sequence of functions $u_{k} *\left(X_{k}\right)$, mapping the process state $X_{k}$ into the optimal control action $u_{k} *$, for every state $X_{k}$ and for every period $k$. DP can be effectively used for this purpose, and the following section is devoted to deriving such a kind of optimal policy.

To make the solution of the problem more easily tractable, so that closed-form solutions (optimal policies) can be obtained, the following simplifying assumptions are made. First, let the product demand $D_{k}$ and functionality $P F_{k}$ in each period $k$ be independently and uniformly distributed in intervals $\left[\delta_{k}, \Delta_{k}\right]$ and $\left[f_{k}, F_{k}\right]$ respectively; numerical solutions are straightforward for some other types of distributions. In addition, ramp-up is not considered, assuming that $C_{k}{ }^{R}=C_{k}$ for every period $k$, and $C_{k}^{R U}=0$; future developments will also include this important aspect. However if the ramp-up phenomenon cannot be neglected, again a numerical solution can be found out by using the model presented above, in particular by including the Expected Ramp-Up Production Cost term (7) in the Expected Operating Cost function (5) and solving numerically the minimization problem, again by the use of DP.

The assumptions above make all the components of the expected operating cost function $\left(E O C_{k}\right)$ be defined differently in the three disjoint intervals $\left[0, f_{k}\right),\left[f_{k}, F_{k}\right)$ and $\left[F_{k},+\infty\right)$. The reader can easily derive the related closed-form definitions, by computing the integrals implied by equations (6) through (9), just recalling that, depending on the specific combination of $P F_{k}, S F_{k}$ and $D_{k}$ occurring in period $k$, quantities $y_{k}, w_{k}, z_{k}$ and $C_{k}$ are defined as in Table 1.

\section{[Insert Table 1 about here]}

It can be easily demonstrated (though the proof is omitted here due to reasons of space) that $E O C_{k}, E P C_{k}, E S C_{k}$ and $E H C_{k}$ are all continuous functions of $S F_{k}$, for every $S F_{k} \in[0,+\infty)$. More particularly, it can be demonstrated that they are continuous functions of $S F_{k}$, over any compact set of the form $\left[0, S_{\mathrm{k}}\right]$, with $S_{k}<+\infty$. This, by Weierstrass theorem, yields to the existence of a minimum for all of these functions, in any compact set of the form $\left[0, \mathrm{~S}_{\mathrm{k}}\right]$, with $S_{k}<+\infty$. The present characterization, in particular for $E O C_{k}$, is fundamental for the existence of the optimal solution of the minimization problem defined above.

Figure 1 shows an example, based on the data reported in Table 2, of Expected Operating Cost function., The two vertical solid lines, parallel to the y-axis, represent the values of $f_{k}$ and $F_{k}$ for the considered case study. For each function, the three different forms, one for each of the intervals cited above, can be easily noticed from the graph. Considering $E O C_{k}$ in particular, it can be noticed that the function is linear and increasing in intervals $\left[0, f_{k}\right]$ and $\left[F_{k},+\infty\right)$, while it is convex in $\left[f_{k}, F_{k}\right]$. This form of $E O C_{k}$ is quite general and representative of the problem itself, and can be shown in many cases of practical interest. In some of these cases, the convexity in $\left[f_{k}\right.$, $\left.F_{k}\right]$ is more evident, and a minimum value for $E O C_{k}$, whose correspondent $S F_{k}$ is internal to [ $f_{k}, F_{k}$ ], can be easily noticed. In some other cases, it can be possible that $E O C_{k}$ is no more convex; in such cases, the function may show two stationary points in $\left[f_{k}, F_{k}\right]$, one local minimum and one local maximum, but it may also be possible that $E O C_{k}$ is concave in $\left[f_{k}, F_{k}\right.$ ]. These last two possibilities are however neither critical for the existence of the minimum for $E O C_{k}$, over any compact set of the form $\left[0, S_{\mathrm{k}}\right]$, with $S_{k}<+\infty$, and nor critical for the existence of the solution to the reconfiguration problem.

[Insert Figure 1 about here]

\subsection{The optimal policy}

http://mc.manuscriptcentral.com/tprs Email: ijpr@lboro.ac.uk 
In this section, the closed-form solution of the optimal reconfiguration problem is presented. The exposition of the procedure and of the related concepts strongly rely on DP theory, assumptions and notation. For reasons of space, the exposition cannot be strictly rigorous and complete; the interested reader is referred to (Bertsekas, 1987) and (Kumar, 1986). Define the optimal cost-to-go function $V_{k+1}\left(X_{k+1}\right)$ at time $k+1$ as:

$$
V_{k+1}\left(X_{k+1}\right)=\min _{\mathrm{u}_{\mathrm{k}+1}, \ldots, \mathrm{u}_{\mathrm{N}-1}} E\left\{-\alpha^{N-(k+1)} \gamma_{N} S F_{N}+\sum_{i=k+1}^{N-1} \alpha^{i-(k+1)} C C_{k}\left(i, u_{i}\right)\right\}
$$

This function represents the cost incurred by applying the portion of the optimal policy from time $k+1$ to time $N$ - 1 , starting at time $k+1$ from state $X_{k+1}$. Assuming the optimality of the cost-to-go function $V_{k+1}\left(X_{k+1}\right)$, one can write the optimal cost-to-go function $V_{k}\left(X_{k}\right)$ at time $k$, for every $k$, as:

$$
\begin{gathered}
V_{k}\left(X_{k}\right)=\min _{\mathrm{u}_{\mathrm{k}}} E\left\{C C_{k}\left(k, u_{k}\right)+\alpha \cdot E_{D_{k+1}, P F_{k+1}}\left[V_{k+1}\left(X_{k+1}\right)\right]\right\} \\
k=0,1, \ldots, N-1 \\
V_{N}\left(X_{N}\right)=-\gamma_{N} S F_{N} \quad k=N
\end{gathered}
$$

where $S F_{N}$ is assumed to be known in advance. Equations (16) are the so-called optimality equations for the optimal system reconfiguration problem represented by DP. It can be proved (for an elegant proof the reader is referred to Kumar, 1986) that an optimal policy for this problem exists if and only if the minimum at (16) is achieved, for every $k$ and for every $X_{k}$.

Equation (16) can be rewritten by explicitly dividing the optimal functionality expansion problem from the optimal functionality reduction problem. This is possible thanks to the definition of $M_{k}\left(u_{k}\right)$ in equation (13). Moreover, by substituting the definition of the control cost in equation (3) into (16), and by denoting with $V_{k}^{L}\left(X_{k}\right)$ and $V_{k}^{U}\left(X_{k}\right)$ the optimal cost-to-go at time $k$ of respectively the expansion and reduction problem, it yields, for every $k=0, \ldots, N$ :

$$
\left\{\begin{array}{l}
V_{k}^{L}\left(X_{k}\right)=V_{k}^{L}\left(S F_{k}\right)=\min _{u_{k} \geq 0}\left\{E+e \cdot u_{k}+E O C_{k}\left(S F_{k}\right)+\alpha E_{D_{k+1}, P F_{k+1}}\left[V_{k+1}{ }^{L}\left(S F_{k+1}\right)\right]\right\} \\
V_{k}^{U}\left(X_{k}\right)=V_{k}^{U}\left(S F_{k}\right)=\min _{u_{k} \leq 0}\left\{R+r \cdot u_{k}+E O C_{k}\left(S F_{k}\right)+\alpha E_{D_{k+1}, P F_{k+1}}\left[V_{k+1}^{U}\left(S F_{k+1}\right)\right]\right\}
\end{array}\right.
$$

By using the definition in equation (4), it yields: 


$$
\left\{\begin{array}{l}
V_{k}{ }^{L}\left(S F_{k}\right)-E+e \cdot S F_{k}=\min _{u_{k} \geq 0}\left\{e \cdot S F_{k+1}+E O C_{k}\left(S F_{k}\right)+\alpha \cdot E_{D_{k+1}, P F_{k+1}}\left[V_{k+1}{ }^{L}\left(S F_{k+1}\right)\right]\right\} \\
V_{k}^{U}\left(S F_{k}\right)-R+r \cdot S F_{k}=\min _{u_{k} \leq 0}\left\{r \cdot S F_{k+1}+E O C_{k}\left(S F_{k}\right)+\alpha \cdot E_{D_{k+1}, P F_{k+1}}\left[V_{k+1}^{U}\left(S F_{k+1}\right)\right]\right\}
\end{array}\right.
$$

Then, defining $H_{k}^{L}\left(S F_{k}\right)=V_{k}^{L}\left(S F_{k}\right)+e \cdot S F_{k}$ for the expansion problem and $H_{k}^{U}\left(S F_{k}\right)=V_{k}^{U}\left(S F_{k}\right)+r \cdot S F_{k}$ for the reduction problem, and assuming that $E=R=0$, without loss of generality, it yields, for every $k=0, \ldots, N$ :

$$
\begin{aligned}
& H_{k}^{L}\left(S F_{k}\right)=\min _{u_{k} \geq 0}\{\underbrace{E O C_{k}\left(S F_{k}\right)+e \cdot(1-\alpha) \cdot S F_{k+1}+\alpha \cdot E_{D_{k+1}, P F_{k+1}}\left[H_{k+1}^{L}\left(S F_{k+1}\right)\right]}_{F_{k}^{L}\left(S F_{k}\right)}\} \\
& H_{k}^{U}\left(S F_{k}\right)=\min _{u_{k} \leq 0}\{\underbrace{E O C_{k}\left(S F_{k}\right)+r \cdot(1-\alpha) \cdot S F_{k+1}+\alpha \cdot E_{D_{k+1}, P F_{k+1}}\left[H_{k+1}^{U}\left(S F_{k+1}\right)\right]}_{F_{k}^{U}\left(S F_{k}\right)}\}
\end{aligned}
$$

It can be demonstrated that, for any compact set of the form $\left[0, S_{\mathrm{k}}\right]$, with $S_{k}<+\infty$, the minimization problems defined by equations (19), which are equivalent to the two separate system functionality expansion and reduction problems, are well-posed problems. This means that the minimum in the right-hand sides of equations (19) is always achieved, for every $k=0,1, \ldots, N-1$. The proof relies on the existence of a minimum for $E O C_{k}\left(S F_{k}\right)$ over the same compact set, as somewhat informally highlighted at the end of Section 3.3, on the convexity of $V_{N}{ }^{L}\left(S F_{N}\right)$ and of $V_{N}^{U}\left(S F_{N}\right)$, and on the induction principle.

The optimal value related to the system functionality expansion problem, defined as $L_{k}$, can be computed, for every $k=0, \ldots, N-1$, as in the following:

$$
L_{k}=\min _{S F_{k} \in \Sigma_{k}^{L}} F_{k}^{L}\left(S F_{k}\right)
$$

where:

$$
\begin{gathered}
\Sigma_{k}{ }^{L}=\left\{0, f_{k}, S F_{k_{1}}^{L^{*}} \cdot 1_{S L_{1}}, S F_{k_{2}}^{L^{*}} \cdot 1_{S L_{2}}, F_{k}\right\} \\
S F_{k_{1}}{ }^{L^{*}}=\frac{-\Delta_{k}+\sqrt{\left(\Delta_{k}{ }^{2}-\delta_{k}{ }^{2}\right)-\mathrm{K}^{L}}}{\mathrm{~K}^{L}-\delta_{k}^{2}} T_{k} \mu \quad ; \quad S F_{k_{1}}{ }^{L^{*}}=\frac{-\Delta_{k}-\sqrt{\left(\Delta_{k}{ }^{2}-\delta_{k}{ }^{2}\right)-\mathrm{K}^{L}}}{\mathrm{~K}^{L}-\delta_{k}^{2}} T_{k} \mu
\end{gathered}
$$

http://mc.manuscriptcentral.com/tprs Email: ijpr@lboro.ac.uk 


$$
\begin{gathered}
1_{S L_{1}}=\left\{\begin{array}{ll}
1 & S F_{k_{1}}^{L^{*}} \in\left[f_{k}, F_{k}\right] \\
0 & S F_{k_{1}}^{L^{*}} \notin\left[f_{k}, F_{k}\right]
\end{array} \quad ; \quad 1_{S L_{2}}= \begin{cases}1 & S F_{k_{2}}^{L^{*}} \in\left[f_{k}, F_{k}\right] \\
0 & S F_{k_{2}}^{L^{*}} \notin\left[f_{k}, F_{k}\right]\end{cases} \right. \\
\mathrm{K}^{L}=\frac{2 \cdot\left[\gamma_{H}+e \cdot(1-\alpha)+\alpha \cdot \phi_{k} \cdot\left(e-\gamma_{N}\right)\right] \cdot\left(\Delta_{k}-\delta_{k}\right) \cdot\left(F_{k}-f_{k}\right)}{\gamma_{P}-P-\gamma_{S}} ; \quad \phi_{k}= \begin{cases}1 & k=N-1 \\
0 & k \neq N-1\end{cases}
\end{gathered}
$$

Similarly, the optimal value related to the system functionality reduction problem, defined as $U_{k}$, can be computed, for every $k=0, \ldots, N-1$, as in the following:

$$
U_{k}=\min _{S F_{k} \in \Sigma_{k}{ }^{U}} F_{k}^{U}\left(S F_{k}\right)
$$

where:

$$
\begin{gathered}
\Sigma_{k}^{U}=\left\{0, f_{k}, S F_{k_{1}}^{U^{*}} \cdot 1_{S U_{1}}, S F_{k_{2}}^{U^{*}} \cdot 1_{S U_{2}}, F_{k}\right\} \\
S F_{k_{1}}^{U^{*}}=\frac{-\Delta_{k}+\sqrt{\left(\Delta_{k}^{2}-\delta_{k}^{2}\right)-\mathrm{K}^{U}}}{\mathrm{~K}^{U}-\delta_{k}{ }^{2}} T_{k} \mu \quad ; \quad S F_{k_{1}}^{U^{*}}=\frac{-\Delta_{k}-\sqrt{\left(\Delta_{k}^{2}-\delta_{k}^{2}\right)-\mathrm{K}^{U}}}{\mathrm{~K}^{U}-\delta_{k}{ }^{2}} T_{k} \mu \\
1_{S U_{1}}=\left\{\begin{array}{ll}
1 & S F_{k_{1}}^{U^{*}} \in\left[f_{k}, F_{k}\right] \\
0 & S F_{k_{1}}^{U^{*}} \notin\left[f_{k}, F_{k}\right]
\end{array} 1_{S U_{2}}= \begin{cases}1 & S F_{k_{2}}^{U^{*}} \in\left[f_{k}, F_{k}\right] \\
0 & S F_{k_{2}}^{U^{*}} \notin\left[f_{k}, F_{k}\right]\end{cases} \right. \\
\mathrm{K}^{U}=\frac{2 \cdot\left[\gamma_{H}+r \cdot(1-\alpha)+\alpha \cdot \phi_{k} \cdot\left(r-\gamma_{N}\right)\right] \cdot\left(\Delta_{k}-\delta_{k}\right) \cdot\left(F_{k}-f_{k}\right)}{\gamma_{P}-P-\gamma_{S}} ; \phi_{k}= \begin{cases}1 & k=N-1 \\
0 & k \neq N-1\end{cases}
\end{gathered}
$$

Figure 2 shows the optimal system functionality expansion and reduction levels related to the same case already treated in Figure 1. The $F_{k}{ }^{L}$ and $F_{k}{ }^{U}$ functions are presented, as well as their minima; these last are indicated in the figure by respectively the square and the circle. $L_{k}$ and $U_{k}$ are the abscissas of respectively the former and the latter.

\section{[Insert Figure 2 about here]}

The formulas reported in equations (20) through (29) are valid, provided that $U_{k} \geq L_{k}$. Moreover, a reasonable assumptions in all cases of practical interest is to require that $e \geq r$.

The optimal policy for the system reconfiguration problem is then presented in the following, by means of boundaries based on the optimal system functionality expansion and reduction levels $U_{k}$ and $L_{k}$ : 


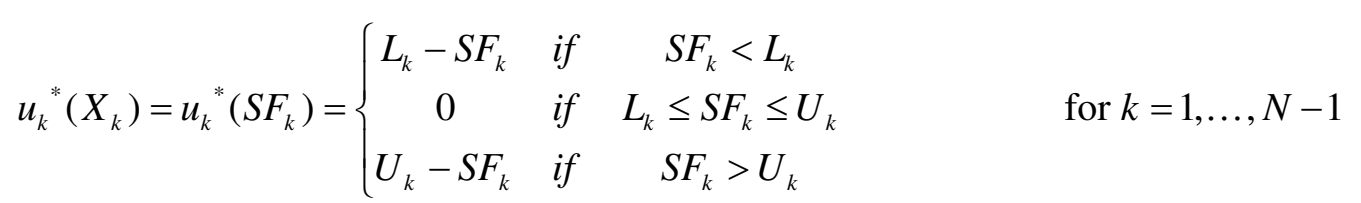

The value of the difference between the optimal boundaries $U_{k}$ and $L_{k}$ can be considered as a measure of reconfigurability. When this value is large, it means the production system will not be often reconfigured, unless some particular scenario is met. On the contrary, the production system may be frequently changed when the difference between $U_{k}$ and $L_{k}$ is small.

Figure 4 shows the iso-lines representing points with equal difference $\left(U_{k}-L_{k}\right.$,), as a function of the unit expansion and reduction costs. The reported iso-lines represent all the situations for which the problem is mathematically defined (given the definition domains of $e$ and $r$ ), i.e. where it is $U_{k} \geq L_{k}$. However, as cited above, in all cases of practical interest the user of the model will take care only of the iso-lines laying under the dashed oblique line (assuming $e \geq r$ ).

The graph states a general tendency occurring when the present model is applied. Indeed, the figure shows that the difference between the values of $U_{k}$ and $L_{k}$, called in the following after the name of optimal interval, increases with the increase of $e$ and with the decrease of $r$. This is a quite obvious result of the cost functions of the problem, as they were defined in the previous pages. Indeed, given a value for $r$, i.e. given a fixed value for $U_{k}$, an increase in $e$ results in a lower convenience in expanding the system functionality, and thus in a lower optimal value for the expansion problem, namely $L_{k}$. The natural lower bound for such a decrease of $L_{k}$ is represented by zero. The converse happens when, given a value for $e$, i.e. given a fixed value for $L_{k}$, an increase in $r$ results in a higher convenience in reducing the system functionality (recall that $r$ is actually a reward for selling the extra functionality), and thus in a lower optimal value for the reduction problem, namely $U_{k}$. The natural lower bound in this second case is represented by $L_{k}$. To be noted that, when $r=0, U_{k}=F_{k}$. Therefore, $F_{k}$ represents the natural upper bound for $U_{k}$ as represented in the graph for very low values of the unit reduction cost. More practically, the level of $r$ under which the iso-lines become parallel one to the other for every value of $e$, namely $r^{*}$ in Figure 3, assures the decision maker that, for values of $r$ lower than this level, the maximum permitted level of system functionality, such that the choice on the $S F_{k}$ is always an optimal choice, is exactly equal to the maximum level of functionality required by the market, namely $F_{k}$. This, in addition to the fact that, in the assumptions of the model, the product functionality will never grow above $F_{k}$, means that a system functionality reduction will never occur in practice, simply because it is never economically convenient to do so. For values of $r$ higher than $r^{*}$, the optimal reduction level $U_{k}$ can be lower than $F_{k}$. In these cases, a reduction of the system functionality is possible, and it happens in particular whenever $P F_{k}$ for a given period is above $U_{k}$, accordingly to the definition of the optimal policy provided by (30).

[Insert Figure 3 about here]

\section{Numerical results}

In this section, a first set of results obtained by applying the proposed model is shown. The capability of the model to support the system designer in the reconfiguration of one type of system functionality is considered, first in a case where functionality expansion costs are very low, and then in a situation where they are much larger. In both cases, the reward values in case of functionality http://mc.manuscriptcentral.com/tprs Email: ijpr@lboro.ac.uk 
reduction are assumed to be very small. Multi-period studies are presented with the objective to show the behaviour of the optimal policy in two extreme situations.

\subsection{Case I: Low expansion costs, low reduction costs}

A sub-contractor in the automotive sector produces all the different product codes concerning different types of steering gear holders (Figure 4b) for the different brands of a big automotive group. These holders are mounted in particular on the different models/variants of pick-ups produced by the group. Since production volumes are expected to be very high for a sequence of years, transfer lines are configured and used to produce the whole part family (Figure 4a). In this specific case transfer lines are rotary, i.e. with rotating turret. The different holders undergo a series of machining operations which are basically the same, except for some special machining operations, in particular those to be realized inside the main cavity of the work-piece, all along its length. To carry out these operations, special tools must be designed and built. The length of the holders is in particular a critical dimension, since typically the longer the length of the work-piece, the longer the special tools, and also the higher the number of operations to be executed inside the cavity (and thus the number of tool inserts needed). The maximum length of the holders requested in a given period represents the product functionality in the considered case.

\section{[Insert Figure 4 about here]}

The sub-contractor knows from the very beginning that, due to the possible introduction of new steering gear holders in the future, as well as the change of some of the already existing work-pieces, the maximum length of the work-pieces to be machined in each period of a given time horizon is independently and uniformly distributed between a minimum and a maximum, defined for each period. The same kind of distribution can be assumed for the production volumes in each period (Table $2 \mathrm{a}$ ).

The system is composed of a single machine, similar to the one shown in Figure 4a, in turn characterized by twelve stations. Each station is equipped with 1 to 4 operating units. Moreover, each operating unit is characterized by 1 to 3 motion axes. Both numerically controlled and non-numerically controlled units are adopted, depending on the machining operations to be executed in each station. The workspace available at each station enables the system to machine all the forecasted types of holders. The same can be stated concerning the number of stations. The reconfiguration action is in the specific case a physical reconfiguration, and regards the special tools to be adopted. The system functionality is assumed to be the length of the tools enabling the system to machine all the different codes requested in a given period. Table $2 b$ shows the model parameters estimated for the present case study. The length of each period is equal to 3 months.

\section{[Insert Table 2 about here]}

A ten-periods (i.e. 30 months) study, based on the numbers reported above, is presented in Figure 5. The salvage value at the end of the time horizon is considered to be $\gamma_{N}=380 \mathrm{keuro} / \mathrm{m}$ (the system lifetime is more than double times the duration of the considered horizon), and the final value of the system functionality is assumed to be $S F_{N}=0.25 \mathrm{~m}$.

Results show, as expected, that reconfiguration costs are so low, compared to the related revenues, that the optimal interval is in every period extremely narrow and equal to zero. Practically, this happens because the value of parameter $e$ is so low that it is convenient to shift the optimal expansion level up to value $F_{k}$, and contemporaneously the value of parameter $r$ is so low that is convenient to shift http://mc.manuscriptcentral.com/tprs Email: ijpr@lboro.ac.uk 
the optimal reduction level down to value $F_{k}$. The proposed optimal policy shows therefore that in this case the optimal choice is to reconfigure in any given scenario; in particular it is always optimal to reconfigure the system up to the maximum value forecasted for the product functionality. As far as the considered specific feature, the system shows then a high degree of reconfigurability, in the sense stated at the end of Section 3.

\section{[Insert Figure 5 about here]}

\subsection{Case II: High expansion costs, low reduction costs}

Consider now a case in which the production problem is the same as the one in case I, but where, if a longer work-piece have to be machined, reconfiguration costs become extremely high. Product functionality is again the maximum length of the holders requested in a given time period, while the system functionality is in this case the maximum length of the holders which can be machined by using the current equipment, considering the machine as a whole. Indeed the reconfiguration action involves, in this second case, the replacement of most of the operating units (e.g. because a higher number of motion axes is needed to perform some new machining operations), and also some relevant additional modifications on the machine structure (such as the modification of the housings for the newly introduced operating units). The new parameters are indicated in Table $3 \mathrm{~b}$. Moreover, due to the different nature of the reconfiguration, the length of each time period is equal to 6 months. Expected production volumes in Table $3 a$ are modified accordingly.

\section{[Insert Table 3 about here]}

A ten-periods (i.e. 60 months) study, based on these numbers, is presented in Figure 6 . The salvage value at the end of the time horizon is assumed to be $\gamma_{\mathrm{N}}=2000 \mathrm{keuro} / \mathrm{m}$ (the system lifetime is assumed to be one year longer than the considered horizon), and the final value of the system functionality is assumed to be $S F_{N}=0.2$.

Results in this case are also in line with the characterization of the optimal interval as a possible measure of reconfigurability, as proposed at the end of Section 3. In fact, the decision maker knows, from the beginning of the considered horizon, that its functionality in the following periods would probably be neither expanded nor reduced. This is mainly because of the wideness of the optimal interval, and holds with a high degree of probability, if the forecasts on $D_{k}$ and $P F_{k}$ will not substantially change in the following periods.

This second case shows in particular the effect of an increase in the unit expansion cost, with respect to case I, given the same value for the unit reduction cost. The wider dimension of the optimal interval is only due to the fact that expanding the functionality here requires high monetary efforts, and thus lead to an optimal expansion boundary which is generally much lower than the one in case I.

[Insert Figure 6 about here] 


\section{Conclusions and future research}

In the present work, the problem of production system reconfiguration has been faced, pointing out the need of taking into account the evolution of technological requirements of the product during the decision making process. The consideration of the technological requirements in the reconfiguration problem represents the major issue of this paper. The reconfiguration problem under uncertainties both on the product demand level and on the technological requirements level, has been modelled as a Markov Decision Problem, for which an optimal policy exists and has been derived in a closed-form. The study of the closed-form solution can help to fully understand the optimality conditions of an analyzed reconfiguration policy.

Ongoing work is developing the optimal policy for a wider set of distributions on the one hand, and taking into consideration the ramp-up costs in the derivation of the optimal policy on the other hand. Further efforts are being spent to better investigate the system functionality, by proposing a metric to define the technological characteristics of production systems which are the most relevant for the reconfiguration problem. Other criticalities to be faced in future research, are related to the fact that some relevant characteristics of production systems can assume only discrete values and some others cannot be expanded or reduced in an easy way. As a first example, the speed factor parameter, which in many practical cases is related to the number of resources of the same type available in the system (e.g. the number of CNC machining centres in a parallel machines FMS), will be considered as an additional decision variable. This will enable the manufacturer to make more complex but at the same time more realistic decisions, based on the change of both the system functionality and the speed factor of the equipment. Other relevant functionalities, which are expected to be derived from the ongoing study on the metric, will be included in the model in order to develop a complete and reliable practical model.

\section{Acknowledgements}

This work is supported by the EC under the IST program, as part of the IP project (FP6-IP-507100) called PROMISE (PROduct lifecycle Management and Information tracking using Smart Embedded systems). The authors would like to thank the anonymous referees, who provided relevant comments on the previous versions of this work.

\section{References}

Angelus, A. , Porteus, E. L., Simultaneous Production and Capacity Management under Stochastic Demand for Perishable Goods, Research Paper NO.1419, Graduate School of Business, Stanford University, Stanford, 1996.

Angelus, A. , Porteus, E. L., Wood, S. C. , Optimal Sizing and Timing of Capacity Expansion with Implications for Modular Semiconductor Wafer Fabs, Graduate School of Business, Stanford University, Research Paper NO.1479R2, 1997.

Asl, F.M., Ulsoy, A.G., Capacity Management in Reconfigurable Manufacturing Systems with stochastic market demand , in Proceedings of IMECE'02, New Orleans, Lousiana, November 17/22, 2002 a. 
Asl, F.M., Ulsoy, A.G., Capacity Management via Feedback control in Reconfigurable Manufacturing Systems with stochastic market demand, in Proceedings of Japan-USA Symposium on Flexible Automation, Hiroshima, Japan, $2002 b$.

Bean, J. C., Higle, J. L. , Smith, R. L., Capacity Expansion under Stochastic Demands, Operations Research, 1991, 40(S2), S210S216.

Bertsekas D.P., 1987, Dynamic Programming: Deterministic and Stochastic models, Prentice Hall, Englewood Cliffs, NJ.

Davies, M.H.A., Dempster, M.A.H., Sethi, S.P., Vermes, D., 1987, Optimal Capacity Expansion Under Uncertainty, Advances in Applied Probability, 19, 156-176.

do Val, J.B.R., Salles, J.L.F, 1999, Optimal Production with Preemption to Meet Stochastic Demand, Automatica, 35, $1819-1828$.

Fong, C. O., Rao, M. R., Capacity Expansion with Two Producing Regions and Concave Costs, Management Science, 1975, 22, 331339.

Freidenfelds J., Capacity Expansion when Demand is a Birth-Death Random Process, Operations Research, 1980, 28(3), 712-720.

Gindy, N. N., Z., Ratchev, S. M., Integrated framework for selection of machining equipment in CIM, International Journal of Computer Integrated Manufacturing, 1998, 11, 311-325.

Koren Y., Heisel U., Jovane F., Moriwaki T., Pritschow G., Ulsoy G., Van Brussel H., Annals of the CIRP, 1999, Reconfigurable Manufacturing Systems, 48, 527-540.

Kumar P.R., Varaiya P., 1986, Stochastic Systems, Estimation, Identification and Adaptive Control, Prentice Hall, Englewood Cliffs, NJ.

Luss H., A Capacity Expansion Model for Two Facilities Types, Naval Res. Logist. Quart., 1979, 26, 291-303.

Luss H., Operations Research and Capacity Expansion Problems: A survey, Operations Research, 1982, 30, 907-947.

Manne A.S., Capacity Expansion and Probabilistic Growth, Econometrica, 1961, 29, pp 632-649.

Manne A.S., Investments For Capacity Expansion Size Location and Time-Phasing, The MIT Press, Cambridge, MA, 1967.

Matta A., Semeraro Q. Edited by, 2005, Design of Advanced Manufacturing Systems, Kluwer Academic Publishers. 
Matta A., Tolio T., Karaesmen F. and Dallery Y., A New System Architecture Compared with Conventional Production System Architectures, International Journal of Production Research, 2000, 38.

Matta A., Tomasella M., Adaptive production systems to react to product change, 18th International Conference on Production Research, University of Salerno, Fisciano (SA), Italy, July $31^{\text {st }}$ to August $4^{\text {th }}-2005$, pp.99-106.

Rocklin, S.M., Kashper, A., Capacity Expansion/Contraction of a Facility with Demand Augmentation Dynamics, Operations Research, 1984, 32, 133-147.

Sinden F.W., The Replacement and Expansion of Durable Equipment, Journal Soc. Ind. Appl. Math., 1960, 8, 466-480. 


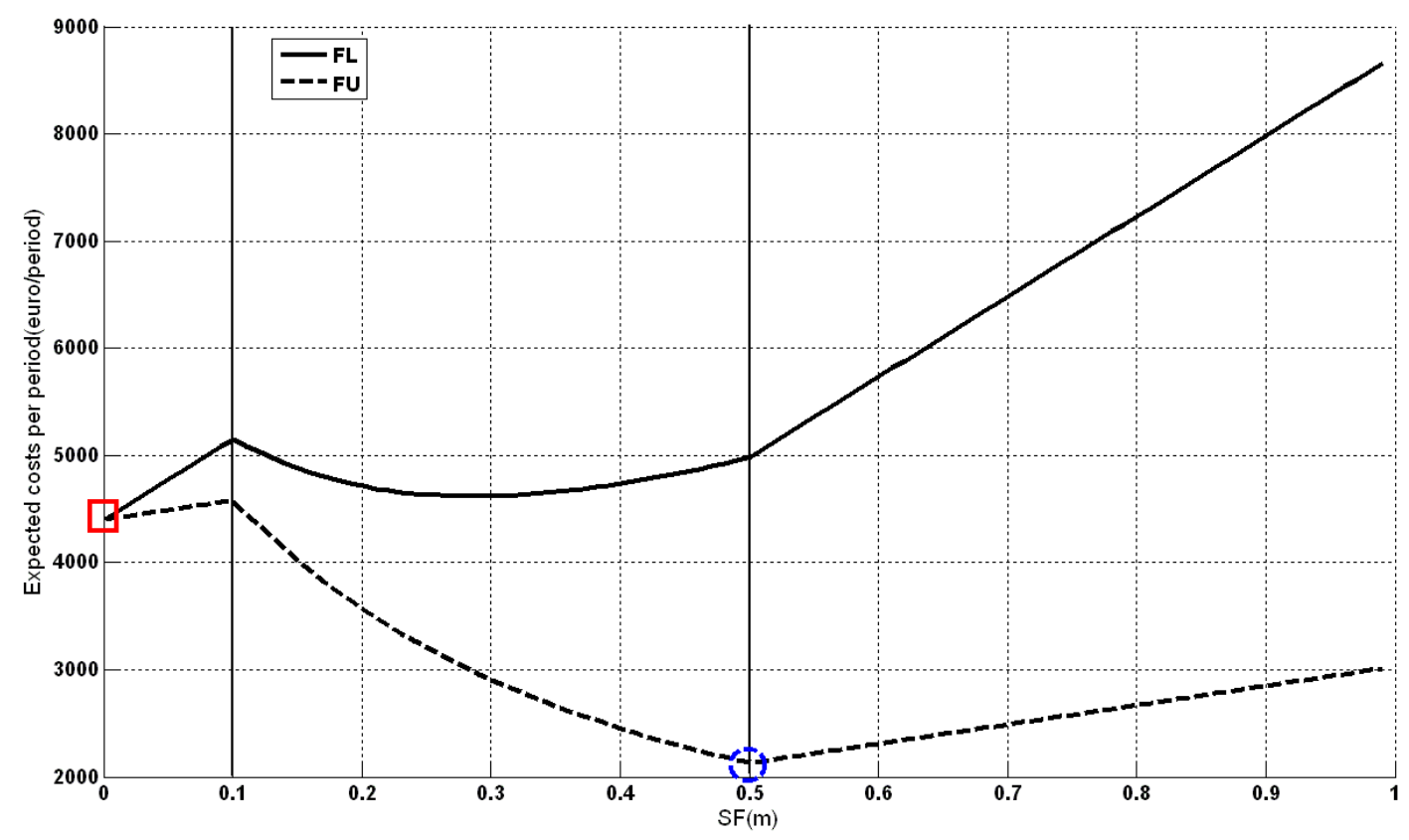

Figure 2 - Optimal expansion and reduction levels in a given single period (case I). 


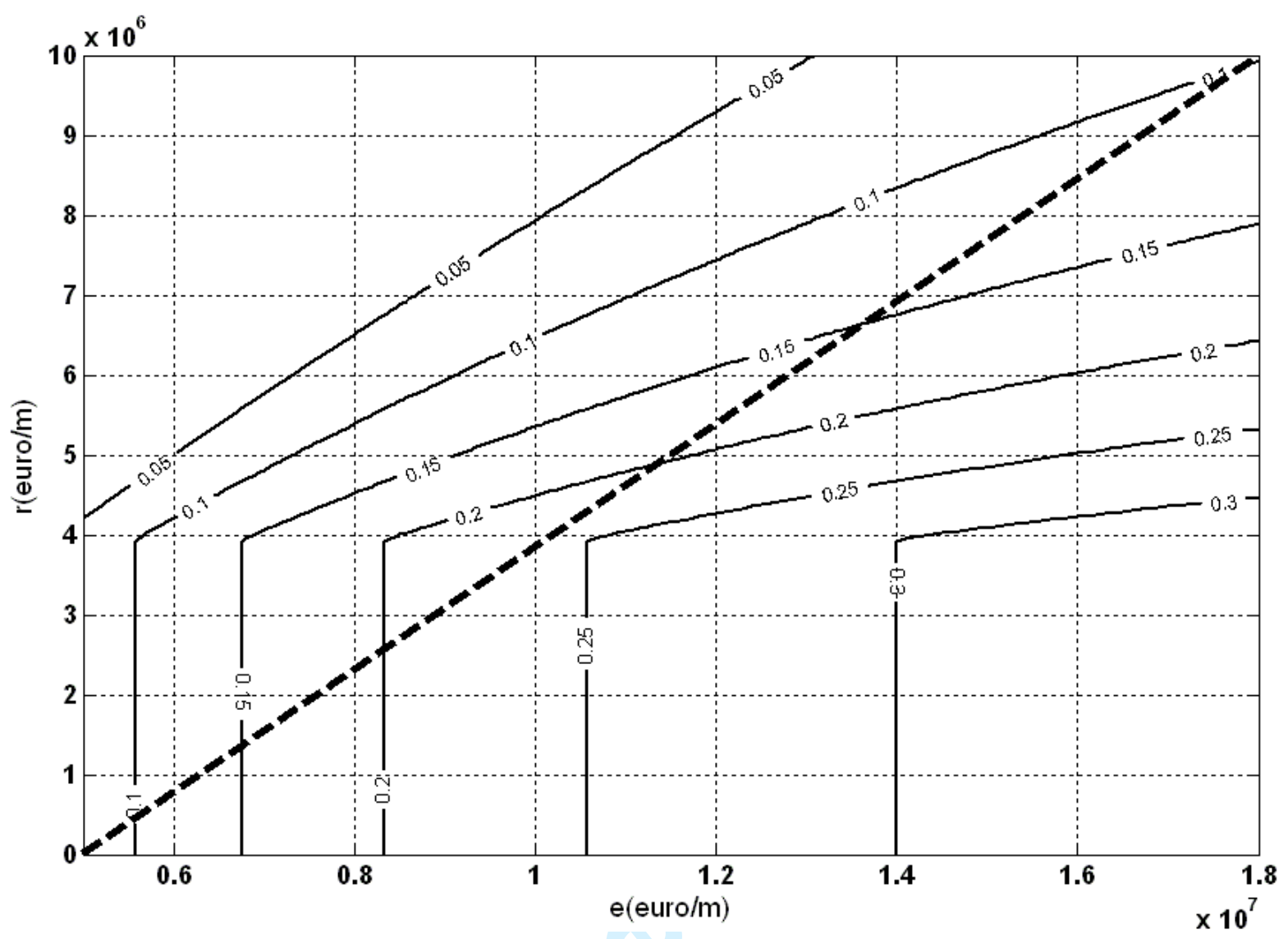

Figure 3 - Dimension of the optimal interval as a function of unit expansion and reduction costs.

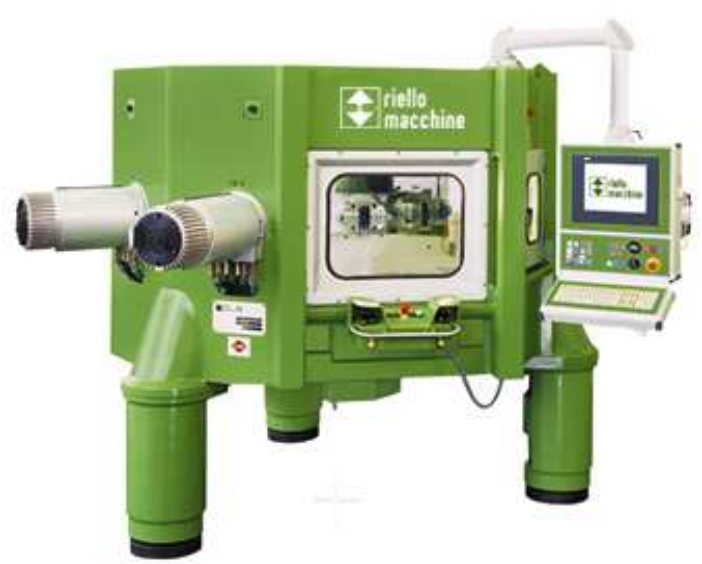

(a)

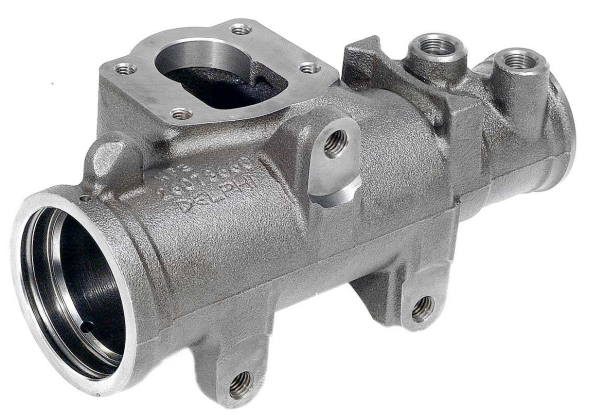

(b)

Figure 4 - A transfer line with rotating turret (a) and a steering-gear holder housing (b) similar to those considered in case I (courtesy of Riello Sistemi SpA, Minerbe (VR) Italy, http://www.riellomacchine.it) 


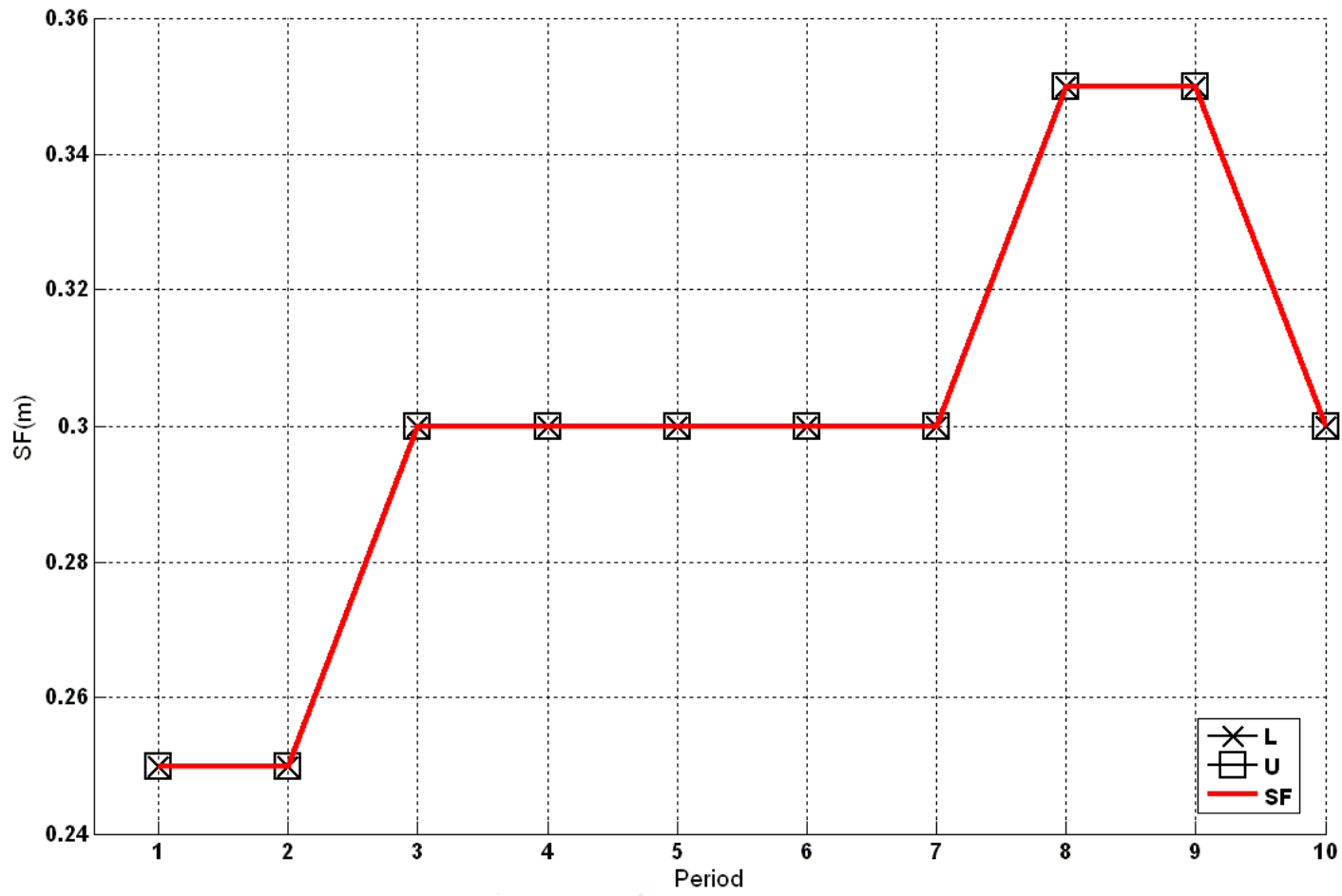

Figure 5 - Multi-period analysis related to case $\mathbf{I}$.

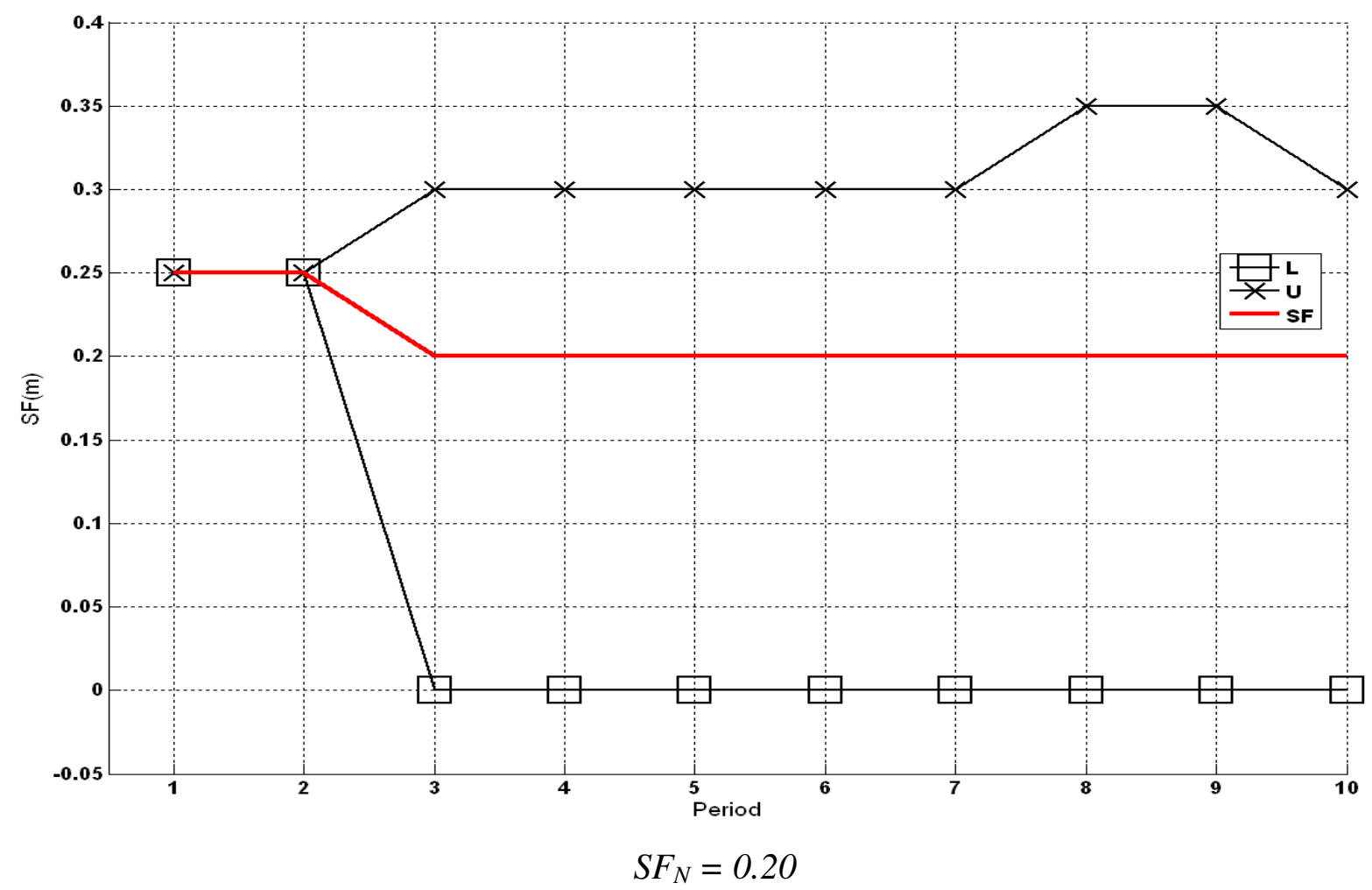

Figure 6- Multi-period analysis related to case II.

http://mc.manuscriptcentral.com/tprs Email: ijpr@lboro.ac.uk 


\begin{tabular}{|c|c|c|c|c|c|c|}
\hline$S F_{k}$ & $P F_{k}$ & $D_{k}$ & $y_{k}$ & $z_{k}$ & $w_{k}$ & $C_{k}$ \\
\hline$S F_{k}<f_{k}$ & $\forall P F_{k}$ & $\forall D_{k}$ & 0 & $D_{k}$ & \multirow{6}{*}{0} & 0 \\
\hline \multirow{3}{*}{$f_{k} \leq S F_{k} \leq F_{k}$} & \multirow{2}{*}{$f_{k} \leq S F_{k} \leq S F_{k}$} & $\delta_{k} \leq S F_{k} \leq C_{k}$ & $D_{k}$ & 0 & & \multirow{2}{*}{$C_{k}$} \\
\hline & & $C_{k} \leq S F_{k} \leq \Delta_{k}$ & $C_{k}$ & $D_{k^{-}} C_{k}$ & & \\
\hline & $S F_{k} \leq S F_{k} \leq F_{k}$ & $\forall D_{k}$ & 0 & $D_{k}$ & & 0 \\
\hline \multirow{2}{*}{$S F_{k}>F_{k}$} & \multirow{2}{*}{$\forall P F_{k}$} & $\delta_{k} \leq S F_{k} \leq C_{k}$ & $D_{k}$ & 0 & & \multirow{2}{*}{$C_{k}$} \\
\hline & & $C_{k} \leq S F_{k} \leq \Delta_{k}$ & $C_{k}$ & $D_{k^{-}} C_{k}$ & & \\
\hline
\end{tabular}

Table 1 - Values of $y_{k}, w_{k}, z_{k}$ and $C_{k}$ for any possible combination of $S F_{k}, P F_{k}$ and $D_{k}$. *Please notice that $w_{k}$ is identically equal to zero because of the fact that the ramp-up phenomenon is not taken into account in this case 


\begin{tabular}{ccccc}
\hline $\mathrm{k}$ & $\delta_{\mathrm{k}}$ & $\Delta_{\mathrm{k}}$ & $\mathrm{f}_{\mathrm{k}}$ & $\mathrm{F}_{\mathrm{k}}$ \\
\hline 1 & 45000 & 240000 & 0.16 & 0.25 \\
2 & 45000 & 255000 & 0.16 & 0.25 \\
3 & 45000 & 255000 & 0.16 & 0.3 \\
4 & 45000 & 270000 & 0.16 & 0.3 \\
5 & 45000 & 270000 & 0.16 & 0.3 \\
6 & 45000 & 270000 & 0.16 & 0.3 \\
7 & 45000 & 285000 & 0.16 & 0.3 \\
8 & 45000 & 285000 & 0.16 & 0.35 \\
9 & 45000 & 285000 & 0.16 & 0.35 \\
10 & 45000 & 255000 & 0.16 & 0.3 \\
\hline
\end{tabular}

(a) Product demand and functionality

\begin{tabular}{cc}
\hline SYSTEM & VALUE \\
PARAMETER & \\
\hline T(months $)$ & 3 \\
$\mu(\mathrm{m} / \mathrm{s})$ & 0.003 \\
$\gamma_{\mathrm{P}}(/$ piece $)$ & 1.6 \\
$\mathrm{P}(€ /$ piece $)$ & 3 \\
$\gamma_{\mathrm{S}}(€ /$ piece $)$ & 2 \\
$\gamma_{\mathrm{H}}(€ / \mathrm{m})$ & 0.4 \\
$\beta$ & 0.97 \\
$\mathrm{e}(\mathrm{k} € / \mathrm{m})$ & 560 \\
$\mathrm{r}(€ / \mathrm{m})$ & 0 \\
\hline
\end{tabular}

(b) System Parameters

Table 2 - Input data for the multi-period case I.

\begin{tabular}{ccccc}
\hline $\mathrm{k}$ & $\delta_{\mathrm{k}}$ & $\Delta_{\mathrm{k}}$ & $\mathrm{f}_{\mathrm{k}}$ & $\mathrm{F}_{\mathrm{k}}$ \\
\hline 1 & 90000 & 480000 & 0.1 & 0.25 \\
2 & 90000 & 510000 & 0.1 & 0.25 \\
3 & 90000 & 510000 & 0.1 & 0.3 \\
4 & 90000 & 540000 & 0.1 & 0.3 \\
5 & 90000 & 540000 & 0.1 & 0.3 \\
6 & 90000 & 540000 & 0.1 & 0.3 \\
7 & 90000 & 570000 & 0.1 & 0.3 \\
8 & 90000 & 570000 & 0.1 & 0.35 \\
9 & 90000 & 570000 & 0.1 & 0.35 \\
10 & 90000 & 510000 & 0.1 & 0.3 \\
\hline
\end{tabular}

(a) Product demand and functionality

\begin{tabular}{cc}
\hline SYSTEM & VALUE \\
PARAMETER & \\
\hline $\mathrm{T}($ months $)$ & 6 \\
$\mu(\mathrm{m} / \mathrm{s})$ & 0.003 \\
$\gamma_{\mathrm{P}}(€ /$ piece $)$ & 1.6 \\
$\mathrm{P}(€ /$ piece $)$ & 3 \\
$\gamma_{\mathrm{S}}(€ /$ piece $)$ & 2 \\
$\gamma_{\mathrm{H}}(€ / \mathrm{m})$ & 0.4 \\
$\beta$ & 0.97 \\
$\mathrm{e}(\mathrm{k} € / \mathrm{m})$ & 17500 \\
$\mathrm{r}(€ / \mathrm{m})$ & 0 \\
\hline
\end{tabular}

(b) System Parameters

Table 3 - Input data for the multi-period case II. 